\title{
O desafio da diversidade religiosa e linguística na educação formal em Burquina Faso: mobilidade estudantil e redes de suporte social
}

\author{
Pingrewaoga Bema Abdoul Hadi Savadogo ${ }^{\mathrm{a}}$, Denise Dias Barros ${ }^{\mathrm{b}, \mathrm{c}}$ \\ aPrograma de Pós-Graduação em Ciências Sociais, Universidade Federal do Rio Grande do Norte - UFRN, \\ Natal, RN, Brasil \\ ${ }^{b}$ Departamento de Fisioterapia, Fonoaudiologia e Terapia Ocupacional, Faculdade de Medicina, \\ Universidade de São Paulo - USP, São Paulo, SP, Brasil \\ 'Programa de Pós-graduação em Terapia Ocupacional, Universidade Federal de São Carlos - UFSCar, \\ São Carlos, SP, Brasil
}

\begin{abstract}
Resumo: O presente artigo aborda, por meio de análise da produção teórico-bibliográfica específica e de observações dos autores, a formação de jovens muçulmanos em Burquina Faso. A temática central vincula-se ao debate mais geral sobre educação e diversidade, pois discute, de um lado, a hegemonia educacional de orientação laica e em língua francesa oficializada pelo Estado e, de outro, a resistência de um segmento da sociedade que prefere inscrever seus filhos em escolas de orientação muçulmana cujo ensino se faz em árabe ou bilíngue (francês e árabe). Descreve-se o contexto sociopolítico em que se constituem as instituições de ensino islâmicas, ressaltando a importância das escolas franco-árabes e das novas instituições universitárias muçulmanas da rede privada de ensino superior. Segue-se uma discussão sobre a contribuição dos jovens formados nesses contextos (dentro e fora do país) para a manutenção e renovação do ensino em seu conjunto. Ressalta-se a presença de ação política de tais grupos, que fazem apelo à noção de cidadania a partir da prática religiosa. Conclui-se que a existência da contribuição islâmica, que permanece como espaço de construção de sentido para um número grande de pessoas e sociedades africanas, é fundamental, mesmo nas dinâmicas pós-coloniais. Esse é o cenário em que a formação/reconstituição de redes sociais dos jovens configura-se em problemática para a qual a Terapia Ocupacional social pode desenvolver ações específicas, tanto para favorecer a mediação de conflitos originados no confronto de valores e práticas sociais distintas, como no processo de reconstrução de redes de sociabilidade.
\end{abstract}

Palavras-chave: Terapia Ocupacional Social, Islã, Cultura, Educação, Juventude.

\section{The challenge of religious and language diversity in Burkina Faso formal education: students' mobility and social networks}

\begin{abstract}
This paper addresses the education of young Muslims in Burkina Faso through relevant literature analysis and the authors' observations, highlighting the pathways of study in Arabic-speaking countries and the social dynamics around them. The central theme is associated with the more general debate about education and diversity, because it discusses, on the one hand, the educational hegemony of secular orientation carried out in French adopted by part of the society and made official by the nation-state; on the other hand, it stresses the movement of another part of society that continues to enroll their children in Muslim schools where teaching is conducted in Arabic or bilingual (French and Arabic). The study describes the sociopolitical contexts that constitute the institutions of Islamic education, emphasizing the importance of Franco-Arabic schools and new Muslim private universities from the non-public higher education network. Following this discussion, there is a debate about the contribution of these young graduated men and women (inside and outside the country) to hold and maintain the educational system.
\end{abstract}

Autor para correspondência: Denise Dias Barros, Universidade de São Paulo, Rua Cipotânea, 51, Cidade Universitária, Butantã, CEP 05360-160, São Paulo, SP, Brasil, e-mail: ddbarros@usp.br

Recebido em 5/7/2013; Revisão em 31/5/14; Aceito em 2/6/2014. 
This paper also highlights the political action of these groups that claims for citizenship through religious practices. We conclude by stressing the existence of the fundamental contribution of Islam, which remains a powerful space for the construction of social and interpersonal meanings even in post-colonial dynamics. This is the scenario in which the reconstruction of networks may be converted into an overall challenge for social occupational therapy to mediate conflicts emerging from the confrontation of values and social practices.

Keywords: Social Occupational Therapy, Islam, Culture, Education, Youth.

\section{Contexto da problemática em estudo}

Nas sociedades do noroeste da África convivem culturas religiosas distintas, notadamente cristãs e muçulmanas, além das práticas históricas locais. Cada uma delas possui tradiçôes e saberes, visão de mundo e estratégias que dão contornos específicos à sua formação, à sua difusão do saber e ao fortalecimento de seus intelectuais e de suas elites. Criaram-se, assim, instituições diferenciadas que orientam os pertencimentos sociais e culturais que disputam a hegemonia no país. Essa complexa dinâmica em Burquina Faso se expressa, também, no campo da regulamentação do uso da língua na interação social. Tal questão continua a ser crucial nas políticas pós-coloniais dos países africanos. O país, com seus 15.224.780 habitantes (INSTITUT..., 2009), possui cerca de 65 línguas, expressóes de práticas históricas bem definidas e, duas línguas usadas no ensino, ambas introduzidas por dinâmicas específicas: seja pela colonização/descolonização seja pela adoção do Islá por grande número de pessoas.

Os dados sobre a relação entre o nível de vida e a escolarização das crianças até 12 anos mostram que em todo o país a taxa de escolarizaçáo das crianças entre sete a 12 anos é de $23,9 \%$ para os segmentos mais pobres e de $81,6 \%$ para os mais ricos. Tal desigualdade é maior no grupo de jovens de 13 a 16 anos, respectivamente, $10,9 \%$ e $62,3 \%$. Quanto à diferença entre população vivendo em meio rural e urbano, no grupo de sete a 12 anos a escolarizaçáo é de 23,3\% nas regióes rurais e 65,8\% nas urbanas (KOMBIANÉ, 2009).

No grupo dos jovens entre 13 e 16 anos, as taxas escolares são, respectivamente, $47,8 \%$ entre os grupos mais pobres e $80,2 \%$ entre os mais ricos. Nota-se que a população rural em Burquina Faso representa $85 \%$ da população total (MINISTÈRE..., 2000). Jean-François Kobiané (2009) analisa os fatores socioculturais e econômicos relacionados ao baixo nível de escolarização assim como o desperdício devido à perda de estudantes dos segmentos sociais mais pobres e marginalizados. Cabe dizer que há diferença importante entre a escolarização de homens e de mulheres, ressaltando-se que apesar dos esforços em mudar esse quadro, a divisáo dos papéis e a valorização do casamento como condição necessária para se alcançar o estatuto de adulto em sua plenitude corroboram para a existência dessa desigualdade na escolarização entre os gêneros. Kobiané (2009) explica as desigualdades educacionais entre as regiōes e entre as áreas rurais e urbanas como efeito conjugado de fatores históricos e de escolhas políticas dos governantes.

A temática do presente artigo vincula-se, de diferentes maneiras, ao debate mais geral sobre educação e diversidade, pois discute a hegemonia educacional de orientaçáo laica e em língua francesa adotada por parte da sociedade e oficializada pelo Estado e, o movimento de outra parte da sociedade, que permanece enviando seus filhos para escolas de orientação muçulmana com ensino em árabe ou bilíngue (francês e árabe). Descreve-se, em primeiro lugar, o contexto sociopolítico em que se constituem as instituiçôes de ensino islâmicas, ressaltando a importância da formação em árabe e francês (escola franco-árabe) e as novas instituições universitárias privadas. Segue-se uma discussão sobre a contribuição dos jovens formados no contexto muçulmano (dentro e fora do país) para a manutenção e renovação do ensino em seu conjunto, enfatizando, ao mesmo tempo a presença de uma açáo política que faz apelo à cidadania, a partir da prática religiosa com base numa linguagem política do Islã (EICKELMAN; PISCATORI, 2004; KEPEL, 2000).

Os procedimentos metodológicos do estudo basearam-se em pesquisa bibliográfica, precedida por um trabalho de campo o qual teve duração de quatro meses, realizado em Ouagadougou (Burquina Faso) cujo objetivo foi, sobretudo, o conhecimento da questão por meio de visitas às instituiçóes e discussóes com pessoas que estudaram em países de língua árabe, conduzida pelo autor principal deste artigo. $\mathrm{O}$ foco central em termos metodológicos foi a busca da bibliografia reconhecida (MAGET, 1953; HAGUETTE, 1999; COMBESSIE, 2007) sobre as temáticas da escolarização, formação universitária na África (notadamente em Burquina Faso), sobre a mobilidade de intelectuais africanos e a história do 
Islã na África do Oeste; além pesquisar documentos oficiais e publicaçóes das associaçôes e instituiçóes muçulmanas em Burquina Faso. Foi possível conhecer e visitar diversas vezes as redes e as instituiçóes islâmicas de ensino, as mesquitas e outros espaços de encontro da juventude que viveu a experiência da mobilidade com a finalidade de estudar em países de língua árabe: Egito, Síria, Líbia e Arábia Saudita.

Entre 15 de novembro e 27 de dezembro de 2010 foram feitas entrevistas semiestruturadas com quatro líderes religiosos e responsáveis de instituiçóes/associaçóes muçulmanas inseridos na política nacional, cinco jovens diplomados inseridos/ as no mercado de trabalho e seis diplomados sem inserção profissional. É preciso dizer, também, que estes quinze colaboradores são militantes ativos/as que atuam em instituições/associaçôes muçulmanas.

O Islã em Burquina Faso possui diferenças internas e divergências importantes. Ele é historicamente dividido entre as confrarias Tidjania (no oeste do país), introduzida por El Hajj Omar Tall, a Qadiriyya (no centro), a Hamaliyya (no norte) e, nos centros urbanos, o Wahhabismo, criado por Muhammad bin Abd al Wahhab em meados do século XVIII. Esse último é majoritário na Arábia Saudita exercendo, também, grande influência no Qatar - países que oferecem bolsas de estudos em Burquina Faso e em toda África do oeste. Atualmente, os maiores conflitos e divergências ocorrem entre os wahhabistas (movimento religioso conservador) e os outros setores da comunidade muçulmana do país. Os wahhabitas assumem como seus os valores culturais da Arábia Saudita que, por sua vez, garante a eles suporte econômico e político (OTAYEK, 1996).

Mesmo que os muçulmanos sejam o segmento mais numeroso (59\%, ou seja, 9.292.000 segundo o Pew Research Center, em 2009) e "detenham" grande poder econômico, são as elites cristãs que mantêm a hegemonia política no campo da educação. De fato, estabelecido pelo precedente Estado colonial francês e pela Igreja Católica, o sistema de educação atual - baseado em modelo francês - foi desenvolvido em detrimento tanto das práticas tradicionais (ligadas à cultura oral das diversas sociedades que compóem o país), quanto do ensino de matriz islâmica, constituído com base no árabe. Entretanto, essa situação não impediu a continuidade e mesmo o desenvolvimento de um conjunto de iniciativas e instituiçóes islâmicas, foco da análise deste artigo. Em outras palavras, discute-se aqui o desenvolvimento de um circuito de ensino por meio de sistema complexo de instituiçóes islâmicas, produzindo, conforme sugere Ousmane Kane (2003), intelectuais que não se expressam em línguas europeias. Appiah (1997), por sua vez, ressaltou que os intelectuais do terceiro mundo resultam de seus encontros com a modernidade e as identidades do ocidente. No caso da África, enfatizou o fato de que os textos se encontrem em português, francês e inglês, correspondendo a identidades nacionais que se constituem como alteridades radicais em relação aos povos não ocidentais (KANE, 2003).

A produção colonial e muito do que ainda se produz hoje carrega a herança de uma epistemologia formada por visóes e conceitos ocidentais. De certa maneira, a luta que se trava na educação em Burquina Faso ilustra esse conflito epistemológico mais amplo, que nesse caso, ocorre entre a epistemologia islâmica, que se expressa em árabe, e os conceitos da modernidade ocidental de fundamento cristão, que se expressam em francês. Existe, afirma Kane (2003), outras bibliotecas na África, além da "biblioteca colonial", que são fundamentais para a construção de sentido de um número grande de comunidades.

Trata-se, para o autor, de ressaltar a existência de extenso material produzido tanto por viajantes como por intelectuais africanos e árabes ao longo do processo histórico de construçáo de conhecimento (desde o século VIII) nas terras do Islã, dâr-es-Islâm (TOUATI; ALEXANDRE, 2000). Somam-se aqui a produção contemporânea da diáspora africana motivada pela busca de conhecimento, resultante do próprio percurso da migraçáo, como no caso dos intelectuais e religiosos que deixam Burquina Faso para estudar em países em que o Islã é a referência hegemônica.

\section{A educação islâmica fundamental e média: olhares plurais}

O acesso à escola, ou seja, a primeira e mais importante instituição à qual se delega a educação formal e a aquisição de competências tanto profissionais como acadêmicas, constitui um espaço social em que se colocam esperanças e importante investimento de longo prazo para viabilizar uma mobilidade social ascendente. Nela, a complexidade e desafio da questão da língua destacam-se, impondo reflexôes e evidenciando um campo de disputas no interior da sociedade. De um lado, as instituiçôes nacionais e o projeto de Estado-Nação erguido sobre o molde francês e, de outro, a sociedade que desenvolve desde o século XV um espaço cultural e religioso de matriz muçulmana.

Burquina Faso conheceu um crescimento importante das escolas do sistema de ensino islâmico 
de tipo madraça ${ }^{1}$ depois de sua independência, e, posteriormente, das escolas franco-árabes. Seu grande número de estudantes permanece significativo mesmo em nossos dias. Segundo as estatísticas de 2007/2008 havia, em todo o território de Burquina Faso, 8.778 escolas primárias, sendo 1.265 públicas e 7.513 privadas. Essas últimas subdivididas em escolas seculares católicas, muçulmanas e protestantes (CONFÉRENCE..., 2009). Cabe lembrar que ainda durante a ocupação administrativa do país, a política colonial estabeleceu a exclusão das línguas nacionais do processo formal de ensino e, também, definiu estratégias de luta contra a influência muçulmana e o lugar do árabe na formação de crianças e jovens. No entanto, como a língua árabe possuía grande prestígio, a administração colonial adotou inicialmente uma forma de parceria estratégica entre o ensino em árabe e em francês. Mas, já em 1903, o colonialismo francês terminou por estabelecer o secularismo, reforçando medidas para desfavorecer as escolas religiosas em geral e, especialmente, aquelas muçulmanas².

As primeiras madraças do país foram criadas entre 1955 e 1957 (GÉRARD, 1997). Mas a escola que iria fortalecer a comunidade muçulmana em Burquina Faso foi fundada em 1965, na capital, Ouagadougou (SANOGO, 2005; CISSÉ, 1989). Por muito tempo, as madraças se desenvolveram, sobretudo, nas cidades, já que requerem recursos financeiros, técnicos e humanos.

A organização do sistema de madraças atual é semelhante ao da rede pública de ensino, ou seja, ela se faz por níveis: primário com seis anos, secundário com três ou quatro anos e o superior que se faz por ciclos, envolvendo a graduação e a pós-graduação. Entretanto, a escola é o único lugar onde os alunos estão em contato com o árabe.

Ao combinar os princípios da escola corânica (educação religiosa) e da escola pública (educação secular), as madraças parecem ser uma forma de síntese entre a tradição muçulmana e a modernidade. Elas se transformam mantendo a construção identitária e a formação baseada no Islã.

Para aqueles que frequentam as instituições de ensino franco-árabes, geralmente oriundos de grupos sociais economicamente desfavorecidos e de regiōes rurais, o acesso à educação constrói-se por meio de um processo particularmente difícil e incerto. As políticas educacionais tendem a negligenciar outros territórios linguísticos (as línguas locais) e, consequentemente, as perspectivas de inserção socioprofissionais são desiguais.

Apesar das dificuldades, as escolas franco-árabes têm formado jovens que buscam trabalho e, ainda, alimentam igualmente um circuito de estudos de nível secundário e superior fora de Burquina Faso ou nas estruturas universitárias islâmicas do país, criadas com financiamento de países como Arábia Saudita e Qatar.

\section{O ensino islâmico: oferta e percurso de formação de nível superior}

Afirma uma máxima muçulmana que é preciso conhecer Deus (Allah em árabe) antes de adorá-lo. Há outra que sublinha que na visão de Allah a adoração do sábio é superior à do inculto. Essas exortações ao conhecimento são propedêuticas da fé, referências fundamentais para compreender o valor social e cultural atribuído à formação e à erudição.

Para aqueles que seguem seus estudos universitários, há três estabelecimentos superiores islâmicos. Dois deles dois estão localizados em Ouagadougou (a capital política) e um, em Bobo Dioulasso (a capital econômica). Tratam-se, respectivamente, do Centro Universitário Polivalente, da Faculdade Al-Aliman Ibn Baz para Educação e Ciência e da Faculdade Imar Al-Fourkane para Educação e Estudos Islâmicos.

As instituiçôes islâmicas de ensino superior foram criadas a partir do ano 2000. Elas propóem aos seus estudantes uma formação no campo das Ciências da Educação (Estudos Islâmicos, Língua e Literatura árabe) e cursos profissionais (Contabilidade e Ciências da Computação). Pretendem, igualmente, valorizar e redinamizar o ensino bilíngue das escolas francoárabes, oferecendo, além da formação acadêmica, ensino técnico-profissional, a fim de favorecer maior participação econômica e política. Assim, os jovens intelectuais que retornam a Burquina Faso após seus estudos em países de língua árabe são os atores ativos dessa estratégia social, religiosa e política, reivindicando desde os anos de 1990 um espaço político maior e falando de uma identidade islâmica cidadã (LEBLANC; GOMEZ-PEREZ, 2007).

Nos anos 1970, devido ao enriquecimento ligado ao aumento do preço do petróleo, as açóes voltadas para o Terceiro Mundo, a luta contra Israel e o regime de apartheid na África do Sul, os países árabes passaram a desenvolver políticas de maior aproximação da África negra (OTAYEK, 1996). Surgiram as políticas de outorga de bolsas de estudos, as quais favoreceram o aumento do número de jovens que fizeram sua formação no exterior sem as garantias de acordos formais entre os países. No entanto, houve nos anos 1980 a criação descontrolada de 
madraças que, mesmo descumprindo as orientaçôes educacionais vigentes, provocaram aumento de demanda por ensino superior no interior do circuito da educação muçulmana.

Portanto, surgiu um conjunto de desafios vinculados, entre outros, à problemática da equivalência curricular que iria ser, posteriormente, um novo e importante campo de conflito. Nesse período assiste-se às dificuldades de inserção socioprofissional vividos por muitos formandos $\mathrm{da}$ primeira geração após a fragilização e no retorno de seus estudos. Consequentemente, o país viveu uma crise na educação envolvendo as escolas de ensino franco-árabe e os subsídios aos mesmos que se realizava por meio de bolsas de estudo.

Sophie Bava (2009), no seu estudo sobre o percurso escolar e as aspiraçóes sociais dos estudantes de países da África subsaariana, analisa suas condiçôes de vida nos países de acolhimento, particularmente na Argélia e no Egito. Em primeiro lugar, a autora nota que há grande complexidade no processo de compatibilização dos sistemas de ensino, de validação dos estudos precedentes quando não existem acordos específicos entre os países envolvidos. Somam-se às questôes administrativas, as dificuldades de integração, seja no Egito seja na Argélia; assim, a imagem idealizada de conhecer as "verdadeiras" "terras do Islâ" podem dar lugar a crises e decepçôes. Aos desafios de estudar no exterior, muitas vezes sem recursos econômicos suficientes, somam-se adversidades que geram questionamentos de base religiosa. Nesse contexto, as estratégias, individuais e coletivas, devem ser suficientes para não se desistir no processo, seja retornando antes de concluir o curso ou mudando a direção para aventuras migratórias distantes dos estudos. De volta ao país com seus diplomas e competências adquiridas, a dificuldade para o reconhecimento oficial de sua formação acentua ainda mais a vulnerabilidade socioeconômica e cultural.

A maioria dos jovens que se diplomaram pelo sistema franco-árabe tem obtido alguma abertura para trabalhar no próprio campo do ensino (ainda que este seja também escasso). Eles parecem possuir uma vantagem sobre os professores "locais" (aqueles formados no próprio Burquina Faso) devido ao prestígio na comunidade muçulmana, ao aumento de experiência e à ampliaçáo de horizontes e de conhecimentos (TRIAUD, 1995). De fato, durante sua estadia - frequentemente longa - no país de acolhimento, eles aprofundam seus conhecimentos $\mathrm{da}$ língua árabe e da cultura local, além daqueles próprios aos diferentes campos disciplinares específicos (GANDOLFI, 2003). Os jovens diplomados que estudaram fora do país são recrutados para lecionar nas instituiçóes de ensino superior e contribuem assim à realização de um dos objetivos explicitados pela Organização Islâmica para a Educação, as Ciências e a Cultura (ISESCO) ao enfatizar que se necessita de programas de preparação de docentes para minimizar os diferentes problemas do ensino em todos os níveis e em todo o território nacional.

No entanto, uma parte significativa dos jovens volta ao país e enfrenta uma série de dificuldades e desafios que ultrapassam, em muitas situaçóes, sua possibilidade de equacionamento. Muitos não encontram trabalho, sentem a ruptura das redes de suporte afetivo das redes de amigos, redes de interdependência ocorrendo situaçóes de deriva e grande ansiedade, dificuldade em constituir família. Enfim, vivem dificuldades, impedimentos ao exercício da participaçáo e dos direitos.

\section{Islã e cidadania: movimentos associativos}

Os muçulmanos têm sido marginalizados no espaço público burquinabể desde os anos 1980 enfatiza Savadogo (2010), sendo que o Estado passou a exercer uma forte pressáo sobre a umma (comunidade constituída por todos os muçulmanos) desde a revolução de Thomas Sankara de 4 de Agosto de 1983, quando o país abandonou o nome colonial de Alto Volta. E, como disseram Leblanc e Gomez-Perez (2007), o Islá apesar de sua maioria demográfica, tem dificuldades para acessar as instâncias de decisóes políticas, pois seus adeptos devem negociar com a elite cristã que tem a hegemonia do aparelho de Estado (LEBLANC; GOMEZ-PEREZ, 2007).

Em meados dos anos 1970, um conflito dentro da Comunidade Muçulmana do Burquina (CMB) passou a criar campos importantes de tensôes devido a acusaçôes de sincretismo e/ou de ocidentalização, levando à divisão da umma em 1986. Ainda que a política de Aboubacar Sangoule Lamizana (1966 a 1980) - segundo presidente do até entáo Alto Volta - permitiu aos muçulmanos de se desenvolvessem economicamente sem, contudo, suplantar politicamente a hegemonia da elite cristã. A grande crise econômica na década de 1980 que afetou toda a sub-região levou à maior marginalização da juventude muçulmana com relaçáo aos espaços de poder econômico e político. Em favor do processo de democratização e pluralismo político efetivo, os jovens organizaram-se e levaram avante uma série de protestos na década de 1990, denunciando cada vez 
mais fortemente a corrupção e o regime autoritário e corrupto (LEBLANC; GOMEZ-PEREZ, 2007).

Retomando o trabalho de Toby Miller (1998), Leblanc e Gomez-Perez (2007) discutem a noção de cidadania cultural religando-a à dimensão religiosa, particularmente ao Islã. Com referência ao contexto da África Ocidental de língua francesa, as autoras definem a cidadania cultural como a expressão da articulação dos consentimentos (negociação) e resistência (reivindicaçôes) dos jovens burquinabês relativas aos padrôes de socialização em vigor. A característica dessa cidadania reside no seu exercício nos espaços paralelos aos do Estado, mas com a intenção de diálogo. Leblanc e Gomez-Perez (2007) enfatizam que esses são espaços com suas próprias economias e modalidades políticas.

É nesse âmbito, político e social, que precisam ser compreendidos os processos de reconstrução das redes de suporte social dos intelectuais formados em países de língua árabe. Ao mesmo tempo, explicita-se a importância do pertencimento a uma comunidade religiosa, relevando a força das associações islâmicas como produtoras de coesão, sobretudo ao reivindicar o papel do Islá na construção da cidadania. Para esses jovens, o desenvolvimento intelectual em países de língua árabe, sobretudo em centros de fluxos transnacionais reconhecidos (caso da Universidade Al-Azhar no Egito, Zitouna na Tunísia ou Qarawiyyine em Fès, Marrocos, além da Arábia Saudita e Síria) significa reafirmar sua identidade muçulmana, promovendo uma trajetória, uma experiência pessoal que é igualmente a expressão de um desejo de realização coletiva.

No entanto, ocorrem distanciamentos e também perda de laços interpessoais. Assim, o retorno para o país de origem implica, muitas vezes, uma necessidade de reconstruir redes de relaçóes e de pertencimento a fim de construir um lugar social, profissional e econômico. Pode ocorrer, nesse processo, um movimento de retomada religiosa, uma vez que as referencia à religião eventualmente fragilizam-se durante a formação no exterior, devido às críticas das práticas e culturas árabes nos países de acolhimento Saint-Lary e Sansão (2011) denominam tal processo de "islamização" ou "reislamização". Em seus trabalhos, os autores analisam a necessidade sentida hoje por um grande número de muçulmanos de experimentar, reativar, reformular, confirmar e reafirmar sua fé. Uma fé que precisa ser articulada tanto ao social como ao político dentro de uma lógica de apropriação crescente do espaço público e de transformação da sociedade seja pela confrontação, seja pelo diálogo e negociação com o Estado.
Um exemplo desse processo pode ser observado na tendência de apropriação do campo de ensino "franco-árabe" pelos jovens que estudaram em centros de excelência de língua árabe no exterior, fomentando o debate público sobre a política educacional e sobre a integração socioprofissional (PARÉ-KABORÉ, 2007). Da mesma forma, a integração, a construção e o fortalecimento das identidades coletivas, através das associaçôes islâmicas são para esses últimos uma nova forma de cidadania cultural.

O território configura-se como o espaço de negociação cultural pelo qual pessoas, grupos e comunidades apropriam-se dos espaços públicos por meio de trocas, produção e valorização de saberes, expressóes estéticas e pela construção aberta e inacabada de projetos políticos e culturais significativos (BARROS, 2004). A juventude africana tem sido em vários momentos da história pós-colonial os motores da transformaçáo social. Os jovens muçulmanos não estão alheios aos processos políticos ${ }^{4}$ e têm sido ativos nos movimentos por práticas cidadãs em espaços públicos ${ }^{5}$ (GOMEZ-PEREZ, 2005; DIOUF, 2003; GOSSELIN, 2008) devido ao fato de serem protagonistas de transformaçōes intensas que remodelam as dinâmicas de inclusão e exclusão na África desde os anos 1990, afirmam Leblanc e Gomez-Perez (2007). Eles lutam contra sua marginalização nas estruturas organizacionais do Islá no Burquina Faso e contra a exclusão dos espaços decisórios em uma política que favorece as elites ocidentalizadas como já ressaltava René Otayek nos anos 1990.

Consoantes com tais objetivos foram criadas a Associação dos Alunos e Estudantes Muçulmanos do Burquina (AEEMB) e o Círculo de Estudo, de Pesquisa e de Formação Islâmico (CERFI), cujo crescimento deve-se à adesão de jovens retornados de formaçáo no exterior, ressaltamos que ambas as associaçôes têm defendido o pertencimento ao Islã como comunidade de fé sem reivindicar vinculação a uma confraria específica. De fato, dentre as cento quarenta e oito (148) associaçóes islâmicas (Le faso.net, 2005) ${ }^{6}$ existentes no Burquina Faso, a AEEMB e a CERFI reagrupam muçulmanos independentemente da sua obediência. Conscientes da situação difícil dos muçulmanos e dos seus desafios, eles buscam adotar posiçóes que não dividam a comunidade muçulmana.

A AEEMB e o CERFI mantêm relações com outras associaçôes em todas as tendências que estejam em acordo com os dogmas islâmicos. Elas estão presentes em diferentes regiôes do país e organizam regularmente encontros, sessóes de formação, colóquios e seminários sobre temas relacionados à 
religião, à educação, à política e às relaçóes sociais. Decorre deste processo, o desenvolvimento de açôes específicas a serem levadas para todas as categorias profissionais e socioculturais do país.

\section{Considerações finais}

As estratégias coloniais garantiram aos franceses e à elite do Estado pós-colonial o controle político do país e, portanto, do sistema educativo nacional, porém, os muçulmanos reorganizaram e realizaram um desenvolvimento paralelo mesmo que em permanente negociação. O sistema de ensino é, assim, um dos efeitos dessa relaçáo de disputa política, social e cultural, além de religiosa. $\mathrm{O}$ ensino muçulmano renovou-se por meio da inclusão de novas disciplinas tais como a matemática, a história, a geografia e mesmo a literatura francesa.

Herdeiros desse passado, a nova geração de intelectuais de língua árabe continua sua ação frente ao que consideram ser uma resistência religiosa e política e, sobretudo, uma luta anticolonial. O conflito entre geraçóes configura outro desafio no interior da umma do Burquina Faso. Os jovens diplomados em países de língua árabe, assim como a juventude muçulmana em seu conjunto, não escondem seus descontentamentos frente à marginalização política expressa na dificuldade de verem reconhecidos seus diplomas e nas consequências ligadas à restrição de espaços de trabalho e de participação social. A juventude muçulmana criticam os mais velhos pelas dificuldades em ascender a posiçóes de poder no interior da própria comunidade. Eles os reprovavam, também, pelo que consideram ser relaçôes de clientelismo com o Estado mantidas pelas geraçóes no poder da comunidade. A contestação dessa juventude fica, então, cada vez mais forte.

A facilidade do acesso à informação no século XXI permitiu uma leitura mais ampla e mais contextualizada das dinâmicas sociopolíticas. Assim, para essa geração configura-se um momento de articulação do diálogo islâmico com noção de cidadania no contexto da modernidade, destacando-se, porém, que as estratégias de reposicionamento têm dificuldades para se impor. Nesse hiato entre expectativas pessoais, investimentos coletivos (de familiares e comunidade) a realização de participação plena na vida econômica criam-se campos de vulnerabilidade de grande contingente da juventude burquinabê.

As identidades são assim fonte de sentidos e de conteúdos simbólicos, culturais, significantes que precisam ser ativados em processos de construção/ reconstrução de possibilidades de vida. A desigualdade social, econômica e cultural reclama a formação de políticas públicas, exigindo, ao mesmo tempo, a formação de novas abordagens e tecnologias de açáo. É nesse campo que acreditamos serem valiosas as possibilidades de contribuição da Terapia Ocupacional Social, tanto no âmbito das açóes voltadas para as pessoas singularmente, quanto junto às comunidades. Trata-se, assim, de trabalhar nas interfaces entre pessoa e sociedade, ampliando as redes de interdependência com foco na noção de pertencimentos múltiplos e de identidades plurais que têm como suporte, segundo Castells (1999), a construçáo de significados derivados de um conjunto de atributos inter-relacionados, os quais prevalecem sobre outras fontes de significado.

\section{Referências}

APPIAH, K. Na casa de meu pai: a África na filosofia da cultura. Rio de Janeiro: Contraponto, 1997.

AUDOUIN, J.; DANIEL, R. L'islam en haute volta à l'époque coloniale. Paris: Harmattan, 1978.

BARROS, D. D. Terapia ocupacional social: o caminho se faz ao caminhar. Revista de Terapia Ocupacional da Universidade de São Paulo, Sáo Paulo, v. 15, n. 3, p. 90-97, 2004.

BAVA, S. Etre étudiant africain à Alger et au Caire au seuil du troisième millénaire. In: Mazzella, S. La mondialisation étudiante: le Maghreb entre Nord et Sud. Paris: Karthala, 2009. p. 347-360. PMid:19932550 PMCid:PMC2832074.

CASTELLS. M. L'ère de l'information. Paris: Fayard, 1999. (Le pouvoir de l'identité, 2).

CISSÉ, I. Introduction à l'étude des medersas au Burkina Faso, de 1960 à nos jours. 1988. 108 f. Monografia (Maîtrise d'histoire)-Universidade de Ouagadougou, Burkina Faso, 1989.

CISSÉ, I. L'islam et le christianisme durant la période coloniale. In: ILBOUDO, J. (Ed.). Burkina... 2000: une église en marche vers son centenaire. Ouagadougou: Presses Africaines, 1996. p. 183-197.

COMBESSIE, J-C. La méthode en sociologie. 5. ed. Paris: La Découverte, 2007.

CONFÉRENCE DES MINISTRES DE L'ÉDUCATION DES PAYS AYANT LE FRANÇAIS EN PARTAGE - CONFEMEN. Ministère de l'enseignement de Base et de l'Alphabétisation. Etude Pasec Burkina Faso. Les apprentissages scolaires au Burkina Faso: les effets du contexte, les facteurs pour agir. 2009. Disponível em: $<$ http://www.confemen.org/wp-content/uploads/2012/06/ Rapport_Burkina_2009.pdf>. Acesso em: 2 jan. 2013.

DIALLO, S. Circuits de commercialisation et prix $d u$ riz-paddy au Mali: cas de l'opération riz segou. 1985. 119 f. Dissertação (DESS Economie du Secteur AgroAlimentaire)-Universidade de Montpellier 1, França, 1985. DIOUF, M. Engaging Postcolonial Cultures: African Youth and Public Space. African Studies Review, 
Cambridge, v. 46, n. 2 p. 1-12, 2003. http://dx.doi. org/10.2307/1514823

EICKELMAN D. F.; PISCATORI J. P. Muslim politics. Princeton: Princeton University Press, 2004.

GANDOLFI, S. L’enseignement islamique en Afrique noire. Cahiers des Études Africaines, Paris, v. 169-170, n. 3, p. 261-277, 2003. Disponível em: <http://etudesafricaines. revues.org/199>. Acesso em: 10 jan. 2013.

GÉRARD, E. Les médersa, un élément de mutation des sociétés africaines. Politique étrangère, Paris, v. 62, n. 4, p. 613-627, 1997. Disponível em: <http:// horizon.documentation.ird.fr/exl-doc/pleins_textes/ pleins_textes_7/divers2/010013254.pdf $>$. Acesso em: 27 out. 2011.

GOMEZ-PEREZ, M. L'islam politique au sud du Sahara: identités, discours et enjeux. Paris: Karthala, 2005.

GOSSELIN, L. A. Le projet Zaca e ses suites (Ouagadougou, Burquina Faso, 2001 à nos jours): marginalisation, résistances et reconfiguration de l'Islam ouagalais. 2008. 186 f. Dissertação (Mémoire de Maîtrise d'Histoire)Université Laval, Québec, 2008.

HAGUETTE, T. M. F. Metodologias qualitativas na sociologia. 6. ed. Petrópolis: Vozes, 1999.

INSTITUT NATIONAL DE LA STATISTIQUE ET DE LA DÉMOGRAPHIE - INSD. Population $d u$ Burkina Faso par région, de 1997 a 2009. 2009. Disponível em: <http://www.insd.bf/fr/>. Acesso em: 12 dez. 2012.

KANE, O. Intellectuels non europhones. Dakar: CODESRIA, 2003. Disponível em: <http://www.codesria. org/IMG/pdf/ousmane_kane.pdf>. Acesso em: 3 jan. 2013.

KEPEL, G. Jihad: expansion et déclin de l'islamisme. Paris: Gallimard, 2000.

KOBIANÉ, J. F. La non-scolarisation des enfants issus de populations marginalisées au Burquina Faso: ampleur, causes et initiatives des pouvoir publics. UNESCO, 2009. Disponível em: <http://unesdoc.unesco.org/ images/0018/001866/186619f.pdf>. Acesso em: 2 jan. 2013.

LEBLANC, M. N. Les trajectoires de conversion et l'identité sociale chez les jeunes dans le contexte postcolonial ouest-africain: les jeunes musulmans et les jeunes chrétiens en Côte d'Ivoire. Anthropologie et Sociétés, Québec, v. 27, n. 1, p. 85-110, 2003. http:// dx.doi.org/10.7202/007003ar

LEBLANC, M. N. L'orthodoxie à l'encontre des rites culturels. Cahiers des Études Africaines, Paris, v. 182, n. 2, p. 417-436, 2006. http://dx.doi.org/10.4000/ etudesafricaines.5985

LEBLANC, M. N.; GOMEZ-PEREZ, M. Jeunes musulmans et citoyenneté culturelle: retour sur des expériences de recherche en Afrique de l'Ouest francophone. Sociologie et sociétés, Montreal, v. 39, n. 2, p. 39-59, 2007. Disponível em:<bibEm $><</$ bibEm $>$ http:// www.erudit.org/revue/socsoc/2007/v39/n2/019083ar. pdf $>$. Acesso em: 28 dez. 2012.

LE FASO.NET. Fédération des associations islamiques du Burkina Faso: l'union enfin retrouvée! Available from: <http://www.lefaso.net/spip. php?page=impression \&id_article $=11523>$. Access in: 14 aug. 2014.

MAGET, M. Guide d'étude directe des comportements culturels: ethnographie métropolitaine. Paris: Civilisations du Sud, 1953.

MILLER, T. Technologies of truth: cultural citizenship and the popular media. Minnesota: University of Minnesota Press, 1998.

MINISTÈRE DE L'ÉCONOMIE ET DES FINANCES. Politique Nationale de Population du Burkina Faso. 2000. Disponível em: <http://www.hsph.harvard.edu/population/ policies/burkina.pop.pdf>. Acesso em: 03 jan. 2013.

OTAYEK, R. L'islam et la révolution au Burkina Faso: mobilisation politique et reconstruction identitaire. Social Compass, Leuven, v. 43, n. 2, p. 233-247, 1996. Disponível em: <http://horizon.documentation.ird. fr/exl-doc/pleins_textes/pleins_textes_6/b_fdi_4546/010007883.pdf>. Acesso em: 03 jan. 2013.

PARÉ-KABORÉ, A. Education Islamique entre non formel et formel: insertion pédagogique et sociale dans le contexte burkinabè. Education Comparée, Paris, n. 62, p. 215-230, 2007.

PEW RESEARCH CENTER. Mapping the global muslim population: a Report on the size and distribution of the world's muslim population. 2009. Disponível em: <www.pewforum.org/newassets/images/reports/ muslimpopulation/muslimpopulation.pdf $>$. Acesso em: 28 dez. 2012.

SAINT-LARY, M.; SAMSON, F. Pour une anthropologie des modes de réislamisation: supports et pratiques de diffusion de l'islam en Afrique subsaharienne. Ethnographiques, Besançon, n. 22, 2011. Disponível em: <http://www. ethnographiques.org/2011/Saint-Lary,Samson>. Acesso em: 7 jan. 2013.

SANOGO, M. L. Les relations entre l'arabe et le français dans le systeme educatif au Burquina Faso. Sud Langues, Dakar, n. 5, 2005. Disponível em: <www.sudlangues. sn/IMG/pdf/doc-108.pdf>. Acesso em: 28 dez. 2012.

SAVADOGO, P. B. A. H. Islam et dialogue de paix au Burquina Faso: le rôle des leaders musulmans, de la parenté et de l'alliance à plaisanterie dans la consolidation de la paix et de la cohésion sociale. In: Freetown, Peace Initiative in West Africa - The Freetown Conference. Panel 6: interaction among various religious communities, including indigenous African religions (suite). $14 \mathrm{dez}$. 2010. (Comunicação oral). Disponível em: <http:// www.initiativedepaix.org/fr/index.php?option=com content\&view=article\&id=103 > . Acesso em: 10 jan. 2013.

TOUATI, M.; ALEXANDRE, P. Le Retour du plein emploi: une nouvelle révolution française. Paris: Anne Carrière Éditions, 2000.

TRIAUD, J. L. Analyses et comptes rendus. Cahiers des Études Africaines, Paris, v. 35, n. 137, p. 286-290, 1995. Disponível em: <http://www.persee.fr/web/ revues/home/prescript/article/cea_0008-0055_1995_ num_35_137_2034_t1_0286_0000_2>. Acesso em: 28 dez. 2012 . 


\section{Contribuição dos Autores}

O primeiro autor foi responsável pela concepção do texto e pela organização de fontes. A segunda autora foi responsável pela redação e revisão do texto.

\section{Notas}

${ }^{1}$ A madraça (ou madraça do árabe) originalmente designa a escola, seja ela secular ou religiosa. Trata-se uma instituição em que as várias disciplinas - literárias, sociais, científicas e religiosas - são ministradas em árabe. Nelas privilegia-se o estudo do Quran (Corão), do Figh (Direito e Jurisprudência) e do Tafsir (interpretação do Corão). A necessidade de se comunicar em francês e o prestígio dessa língua levou à introdução de programas com ensino em árabe e em francês. No entanto o árabe guarda grande apreço na sociedade por seu caráter religioso e de língua sagrada.

${ }^{2}$ De 1906 a 1950, a administração colonial tomou medidas para maior regulação do Islã e dos marabus. Esses últimos, que têm como hábito deslocarem-se de aldeia em aldeia, só poderiam deslocar-se mediante autorização escrita conferida pela administração (CISSÉ, 1996). A administração colonial não era favorável a "um Islã negro", apenas se separado das raízes árabes e dissociado da política (DIALLO, 1985; AUDOUIN; DANIEL, 1978).

3 "burquina" é um adjetivo vindo de "burquindi" que em mooré (língua dos Mossé) traduz o conceito da integridade. "Faso" significa em Diula (língua falada no oeste do país) a pátria. Aí, "burquinabê" é composto de "burquina” e do sufixo "bê" que em fulfuldé (língua dos Fula) expressa a ideia do pertencimento. Por conta dessa realidade linguística, usaremos ao longo do texto a palavra "burquinabê" para nomear o(s) habitante(s) do Burquina Faso.

${ }^{4}$ Sobre a emergência da juventude no contexto do Islã em países do noroeste da África, ver Leblanc (2003, 2006).

${ }^{5}$ Espaço de discurso e de expressão não verbal mais ou menos livre que estimulam a troca de ideias conflitantes.

${ }^{6}$ Dados do jornal "Le faso.net" . 